\section{Meningitis in a Patient with Previously Undiagnosed Crohn's Disease}

\section{To the Editor:}

Crohn's disease (CD) is a chronic inflammatory bowel disease with variable clinical presentation. An aggressive fistulizing pattern is possible and over one-third of $\mathrm{CD}$ patients will experience recurring fistulas during their disease course. ${ }^{1}$ Fistulization is a manifestation of the transmural nature of this disease, ${ }^{2}$ but fistulas to the epidural space are quite unusual. ${ }^{3}$

Herein we report a case of a male patient who presented to the medical emergency department with meningitis. Physical examination revealed multiple perianal and an abdominal fistula and subsequent complementary studies confirmed the presence of $\mathrm{CD}$.

A 26-year-old man was admitted to the emergency room because of high fever, severe headache, acute confusion, nausea, and vomiting. On admission his body temperature was $39^{\circ} \mathrm{C}$, heart rate 120 , respiratory rate 16 , and blood pressure 103/55 mmHg. On physical examination the patient was confused, not oriented to person, place, or time. Kerning and Brudzinski signs were present but no Babinski or clonus. Ophthalmologic examination revealed papilloedema. There was no otitis, pharyngitis, or sinusitis and heart/lung examination was normal. Abdominal and pelvic examination revealed a large abdominal cutaneous fistula in the lower right quadrant and multiple perianal fistulas. Laboratory results upon admission showed leukocytosis (WBC of $23.2 \mathrm{G} / \mathrm{L}$ with $92 \%$ of PMN), thrombocytosis

Copyright (C) 2009 Crohn's \& Colitis Foundation of America, Inc. DOI 10.1002/ibd.20641 Published online 4 August 2008 in Wiley InterScience (www.interscience.wiley.com).
(689 G/L), and increased C-RP levels ( $20 \mathrm{mg} / \mathrm{dL}$ to a normal of $<1 \mathrm{mg} / \mathrm{dL}$ ). A head computed tomography (CT) scan revealed diffuse cerebral edema and lumbar punction was not performed initially. The patient was given, empirically, intravenous meropenem, vancomycin, and metronidazole. Two days later a lumbar puncture was unsuccessfully tried. Since the clinical symptoms and signs were highly suggestive of meningitis and the patient was recovering very well with antibiotic treatment the lumbar puncture was deemed dispensable. When the patient recovered he revealed that the perianal fistulas appeared 7 years ago and the abdominal fistula in the last 6 months but he hid this findings from his family and never sought medical help. A certain degree of mental impairment was obvious.

After full recovery, a colonoscopy was performed and revealed severe inflammation of the rectum with a small orifice at the posterior wall corresponding, probably, to a fistulous tract. A similar process of severe inflammation was also present at the terminal ileum. Endoscopic and histologic findings were compatible with CD. Severe transmural

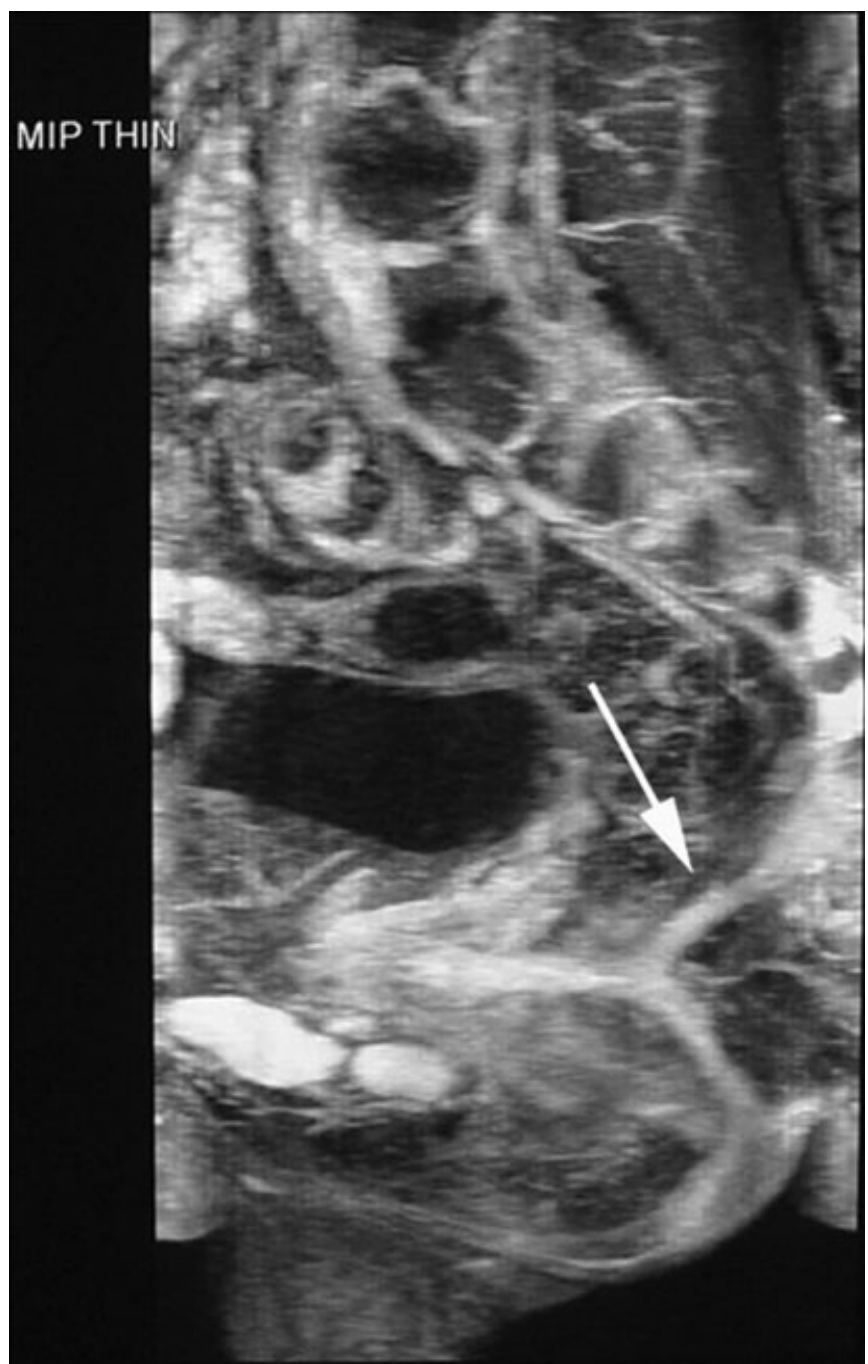

FIGURE 1. Thin sagittal maximum-intensity-projection (MIP) reconstruction of a 3D FLASH sequence of the pelvis shows a posterior sinus tract collecting in a precoccygeal abscess (arrow). 


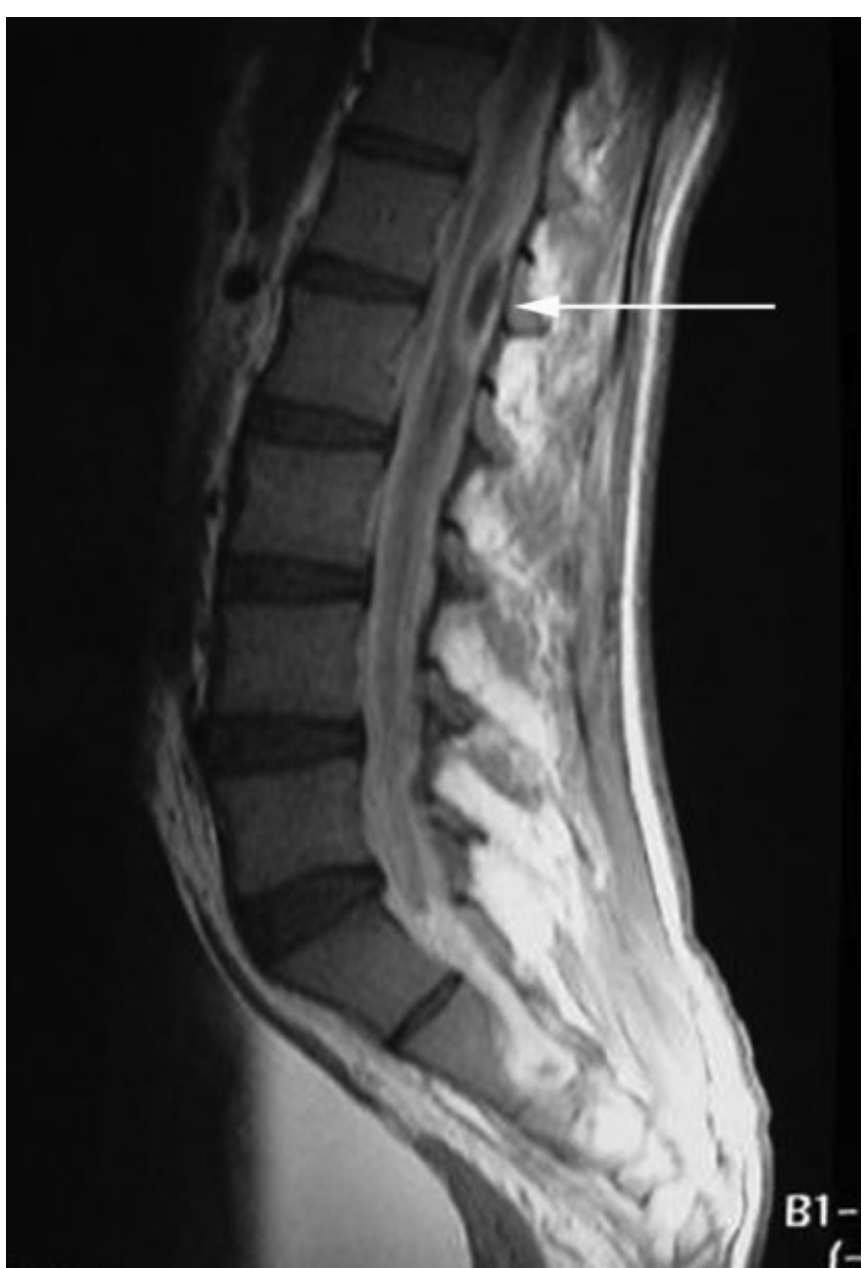

FIGURE 2. Sagittal T1-weighted sequence of the lumbar spine reveals a hypointense lesion at the posterior epidural space (arrow).

thickening of the ileum and a fistula between the small bowel and the abdominal wall were clearly visible at abdominal CT scan. Magnetic resonance imaging (MRI) revealed a complex perianal suprasphincteric fistula with a posterior direction, ending on a presacral and precoccygeal abscess (Fig. 1) with periradicular leptomeningeal infiltration. MRI also revealed a second epidural abscess at the level of L1-L2 (Fig. 2).

The patient was maintained on therapy with ciprofloxacin and metronidazole. Ileocecal resection was performed with drainage and curettage of presacral/precoccygeal abscess. A temporary ileostomy was created and at the last radiologic control both abscesses had disappeared.
The incidence of spinal epidural abscess increased in the last decades. ${ }^{4} \mathrm{~A}$ significant improvement in outcomes occurred in the last years but, even so, there is still a $15 \%$ mortality rate and $38 \%$ of patients remain with neurologic dysfunction. ${ }^{5} \mathrm{CD}$ is not usually mentioned as a predisposing factor for spinal epidural abscess. ${ }^{4}$ Only a few case reports have been published and some document an association with meningitis. ${ }^{3,6-9}$ Direct fistulization from the gastrointestinal tract is a potential source for infection in such cases. However, since a responsible fistula is not identified in all cases and there is a concurrence of vertebral osteomyelitis in a fairly significant number of these patients, it is possible that spinal involve- ment may result from hematogenous spread. ${ }^{3}$ In our case, we had 2 distinct abscesses, 1 with a definitive fistulous communication with the affected rectum but the other with no visible fistulous communication to the small or the large bowel. Therefore, the presacral and precoccygeal abscess resulted from direct fistulization, but it is reasonable to assume that the abscess at the L1-L2 level could be the result of hematogenous dissemination.

It seems that there is a male predominance in patients with CD complicated by epidural abscess formation. Our case confirms this finding but, until now, no reasonable explanation was found for this male predominance. Maggiore et $\mathrm{al}^{3}$ speculated that this observation could be the result of underreporting of all cases.

Meningitis and epidural abscesses are very serious complications and a prompt diagnosis is essential. Clinical findings such as persistent headache and/or persistent low back pain in a patient with $\mathrm{CD}$ are warning signs. A thorough radiologic investigation by MRI and/or CT must be promptly warranted in such cases to exclude potential lifethreatening epidural abscesses. Therefore, radiology is essential for diagnosis and if meningitis is suspected a lumbar puncture must be performed unless there is suspicion of raised intracranial pressure. In such cases a brain CT scan is common practice. Our patient had the "classic triad" of fever, stiff neck, and alterations in mental status. He also had multiple clinical signs of meningeal inflammation and intracranial hypertension such as Kerning's sign, Brudzinki's sign, and papilloedema. The diagnosis of meningitis was straightforward and lumbar puncture in these circumstances has the risk to cause brain herniation and could be postponed or not performed. ${ }^{10,11} \mathrm{We}$ tried to perform it after a 48-hour delay but since it was unsuccessful and the patient was doing well, another attempt was deemed not necessary.

In our case there was no previous 
history of CD but only because the patient never sought medical help. Physical examination revealed some signs frequently related to $\mathrm{CD}$, and abdominal and pelvic imaging by MRI clearly demonstrated the abscesses and the fistulization from the gastrointestinal tract. If the external fistulas were not present, the diagnosis would be more difficult.

Although percutaneous CTguided drainage of epidural abscesses is feasible, ${ }^{12}$ a surgical consultation is essential in the cases for which a fistulization is clearly demonstrated. In our case the abscess at the L1-L2 level disappeared only with antibiotic treatment, but surgery was necessary to resolve the presacral abscess. Temporary ileostomy was created in order to help the control of rectal and perianal fistulizing disease. Diverting the intestinal transit was also performed in 1 of the first reported cases of rectalepidural fistula. ${ }^{6}$

In conclusion, this case demonstrates that even in the 21 st century there is some reluctance to accept $\mathrm{CD}$, especially in unfavored social backgrounds, in such a way that only a rare and special complication forced a patient to search medical attention for the first time. On the other side, it is important to remember that severe headaches and/or persistent low back pain in patients with $\mathrm{CD}$, especially if the patient has fever, should warrant a prompt radiologic investigation to exclude neurologic involvement by fistulas and/or spinal epidural abscesses.

Nuno Almeida, MD $^{1}$ Francisco Portela, MD $^{1}$ Pedro Oliveira, $\mathrm{MD}^{2}$ Alexandre Duarte, $\mathrm{MD}^{3}$ Carlos Gregório, $\mathrm{MD}^{1}$ Dário Gomes, $\mathrm{MD}^{1}$ Hermano Gouveia, $\mathrm{MD}^{1}$ Maximino Correia Leitão $\mathbf{P h D}^{1}$

${ }^{1}$ Gastroenterology Department

${ }^{2}$ Radiology Department

${ }^{3}$ Surgery 1 Department

Coimbra University Hospital Coimbra, Portugal

\section{REFERENCES}

1. Ramsay DB, Petinaux B, Borum M. Pneumoencephalomeningitis complicating Crohn's disease: a case report. Am J Gastroenterol. 2007;102:2356-2357.

2. Sands BE. Crohn's disease. In: Sleisenger and Fordtran's Gastrointestinal and Liver Disease, 8th ed. Philadelphia: WB Saunders; 2002. p 2459-2498.

3. Maggiore R, Miller F, Stryker S, et al. Meningitis and epidural abscess associated with fistulising Crohn's disease. Dig Dis Sci. 2004; 49:1461-1465.

4. Gelfenbeyn M, Goodkin R, Kliot M. Sterile recurrent spinal epidural abscess in a patient with Crohn's disease: a case report. Surg Neurol. 2006;65:178-184.

5. Reihsuas E, Waldbaur H, Seeling W. Spinal epidural abscess: a meta-analysis of 915 patients. Neurosurg Rev. 2000;23:175-204.

6. West D, Russell TR, Brotman M. Rectalepidural fistula complicating Crohn's enterocolitis. Dis Colon Rectum. 1983;26:622-624.

7. Hefter H, Piontek M, Aulich A. Bacterial meningitis and dorsal spinal dural abscess caused by Crohn's disease. Neurology. 1991; 41:606-608

8. Piontek M, Hengels KJ, Hefter H, et al. Spinal abscess and bacterial meningitis in Crohn's disease. Dig Dis Sci. 1992;37:1131-1135.

9. Wallace JR, Luchi M. Crohn's disease complicated by meningitis and spinal epidural abscess. Clin Infect Dis. 1995;20:1428-1429.

10. Fitch MT, Van de Beek D. Emergency diagnosis and treatment of adult meningitis. Lancet Infect Dis. 2007;7:191-200.

11. Joffe AR. Lumbar puncture and brain herniation in acute bacterial meningitis: a review. J Intensive Care Med. 2007;22:194-207.

12. Cassagnou M, Notteghem B, Cotton A, et al. Percutaneous drainage of a presacral and spinal extra-dural abscess complicating Crohn's disease. Gastroenterol Clin Biol. 1996;20:689-692.

\section{Campylobacter fetus Meningitis in a Patient with Crohn's Disease}

\section{To the Editor:}

Campylobacter fetus is an uncommon cause of meningitis in adults. However, Gazaigne et $\mathrm{al}^{1}$ have reported that bloodstream infection with $C$. fetus

Copyright (C) 2009 Crohn's \& Colitis Foundation of America, Inc. DOI 10.1002/ibd.20686

Published online 17 September 2008 in Wiley InterScience (www.interscience.wiley.com). should be suspected in elderly patients, immunodeficient patients, and patients with cardiovascular damage. Moreover, the administration of steroids and infliximab is considered to be a risk factor that promotes bacterial infections. Here, we report a case of Crohn's disease (CD) that was complicated with $C$. fetus meningitis. To our knowledge, this is the first report of meningitis caused by C. fetus in a patient with CD.

A 40-year-old man was diagnosed with CD in 1988 and underwent right hemicolectomy and ileectomy in the same year due to perforation of the ileum. In the subsequent 2 decades he was treated with prednisolone $(15 \mathrm{mg})$ and mesalazine $(2250 \mathrm{mg})$. In 2008 he was admitted to another hospital because of massive bloody stool in the absence of any other abdominal symptoms. To treat the bloody stool the patient was medicated with infliximab. His bloody stool disappeared gradually but then reappeared 4 weeks later. Since the patient was in hypovolemic shock and required a blood transfusion, he was referred to our hospital. Initial blood tests performed upon admission revealed white blood cell counts of $14,800 / \mathrm{mm}^{3}$, red blood cell counts of $1.89 \times 10^{6} / \mathrm{mm}^{3}$, hemoglobin levels of $4.8 \mathrm{~g} / \mathrm{dL}$, and Creactive protein levels of $1.0 \mathrm{mg} / \mathrm{dL}$. After conservative therapy the patient's condition improved promptly. However, on admission, the patient also had a high fever and a severe headache without neck stiffness. Although antibiotic therapy consisting of $6 \mathrm{~g} /$ day piperacillin was started, these symptoms did not improve. A lumbar puncture showed that the cerebrospinal fluid (CSF) had a cell count of $344 / 3 \mathrm{~mm}^{3}$ with mononuclear and polynuclear pleocytosis, total protein of $33 \mathrm{mg} / \mathrm{dL}$, and glucose of 68 $\mathrm{mg} / \mathrm{dL}$. C. fetus was isolated from the CSF, blood, and stool after culture. Consequently, $1 \mathrm{~g} /$ day erythromycin was administered. The patient's symptoms then improved promptly.

Three separate species of Campylobacter have been identified, namely, 